\title{
The Variations of Concentrations, Profiles and Possible Sources of Metals and Polycyclic Aromatic Hydrocarbons in $\mathrm{PM}_{10}$ from Lanzhou, China
}

\author{
Yunjiang $\mathbf{Y u}^{1,2^{*}}$, Qiong Wang ${ }^{2,3}$, Liangzhong $\mathrm{Li}^{1}$, Peng Sun ${ }^{4}$, Yanping Zhang ${ }^{2}$, \\ Haipeng Lin ${ }^{5}$, Jianhua Chen², Bigui Lin ${ }^{1}$, Mingdeng Xiang ${ }^{1}$ \\ 'South China Institute of Environmental Science, MEP, Guangzhou 510535, China \\ ${ }^{2}$ Chinese Research Academy of Environmental Sciences, Beijing 100012, China \\ ${ }^{3}$ Institute of Environmental Health and Related Product Safety, China CDC, Beijing 100021, China \\ ${ }^{4}$ State Key Laboratory of Advanced Metallurgy, University of Science and Technology Beijing, \\ Beijing 100083, China \\ ${ }^{5}$ China Institute for Radiation Protection, Taiyuan 030006, China
}

Received: 2 December 2015

Accepted: 18 January 2016

\begin{abstract}
Metals and polycyclic aromatic hydrocarbons (PAHs) are ubiquitous pollutants in airborne particulate matter. In order to better understand the concentrations and origins of metals and PAHs bound to particulate matter in Lanzhou city in northwest China, six metals $(\mathrm{Cu}, \mathrm{Zn}, \mathrm{Ni}, \mathrm{Pb}, \mathrm{Cd}$, and $\mathrm{Cr}$ ) and 16 selected PAHs in 108 particulate matter samples were quantified by inductively coupled plasma/mass spectrometry (ICP-MS) and gas chromatography/mass spectrometry. Results demonstrated that metals and PAHs in the ambient air of Lanzhou city showed regional and seasonal trends, and their concentrations were higher than those in several other Asian and European cities. The high molecular weight PAHs in winter were higher than in summer in both Xigu District and Yuzhong town. The principle components analysis (PCA) method was applied to analyze the sources of metals bound to particulate matters $\left(\mathrm{PM}_{2.5}, \mathrm{PM}_{10}, \mathrm{TSP}\right)$ and PAHs bound to $\mathrm{PM}_{10}$, and results showed that vehicle emissions, coal combustion, and oil combustion were probably the main sources of metal and PAHs in Lanzhou PM.
\end{abstract}

Keywords: metal, polycyclic aromatic hydrocarbons (PAHs), particulate matter, air, source identification

*e-mail: yuyunjiangteacher@163.com 


\section{Introduction}

Atmospheric particulate matter (PM) is an important pollutant, and much research has been published about their morphological/physical characteristics, concentrations, epidemiological effects, and effects on climate processes $[1,2]$. Atmospheric PM is also an indicator for evaluating air quality. Atmospheric levels of $\mathrm{PM}_{10}$ and $\mathrm{PM}_{2.5}$ are monitoring indicators in the latest ambient air quality standards in China, while the toxic chemical compounds absorbed onto the particles were not used as factors. Actually these compounds, including metals and polycyclic aromatic hydrocarbons (PAHs), which have become a major research issue, have the more serious health risk [3]. Widespread metals pollution causes serious risks to human health, and has brought adverse health effects to kidneys, livers, and nervous system from metals exposure [4, 5]. PAHs, which are stable, hydrophobic, and persistent chemicals in the environment, have been reported to be carcinogenic and mutagenic. Previous studies have shown that the levels of metals and PAHs absorbed onto PM were higher in China than in developed countries, and also higher than the air quality standards of WHO and the EU [6-8]. Different routes of contaminant exposure cause different adverse effects. We find that the same chemical has a lower RfD value in inhalation exposure than other exposure pathways, meaning that humans have higher health risks through inhaling one chemical than other exposure pathways [9]. Studying the variations of concentrations and possible sources of metals and PAHs absorbed onto PM in air is of considerable significance.

This work investigates the metals and PAHs absorbed onto $\mathrm{PM}_{10}$ in Lanzhou city, which is an industrial city in northwest China. Lanzhou has serious air pollution because of a large number of petrification and metallurgy industries and huge coal consumption. In addition, due to the special topography of the valley basin and climatic characteristics of the stable atmospheric layer, the air pollution of Lanzhou is more serious. Our previous work showed that the health risks of PM were within an

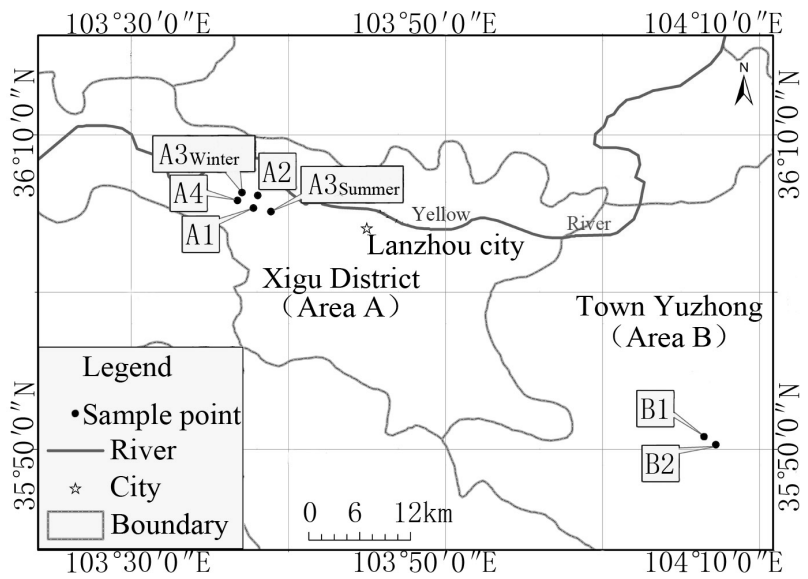

acceptable scope (below $1 \times 10^{-6}$ ), but the health risks of metals were exceeding the acceptable scope of USEPA (below $1 \times 10^{-4}$ ), and the risks of PAHs were exceeding the acceptable scope of Canada (below $1 \times 10^{-5}$ )[9]. The values of urinal 1-OHP in children, which is the indicator for assessing exposure of PAHs, were higher than in adults[10], and we propose taking some effective measures to improve this situation. Therefore, the source analysis of metals and PAHs is particularly important for making measures. Meanwhile, the manner of attempting to analyze the source of metals and PAHs simultaneously is more accurate and comprehensive.

\section{Materials and Methods}

\section{Airborne PM Sampling}

Xigu and Yuzhong, located west and southeast of Lanzhou, respectively, were selected as study areas (Fig. 1). Xigu is the largest petrochemical industry base in Western China, which includes Petrochina Co. Ltd. (comprising oil refineries, chemical fertilizer plants, a petrochemical plant, a rubber factory, a sewage treatment plant, etc.), Xigu Thermoelectric Co. Ltd., and New Western Vinylon Co. Ltd. These companies generate major air pollution. Yuzhong has a primarily agricultural economy, so its industrial pollution is minimal.

TSP, $\mathrm{PM}_{10}$, and $\mathrm{PM}_{2.5}$ samples collection was completed in July 2010 and January 2011, and followed ambient air quality technical specification HJ/T194-2005. Samples were collected using quartz fiber filters (Diameter $90 \mathrm{~mm}$, Whatman Inc., Freiburg, DE) with high-volume air samplers equipped with a cutting head for 2.5, 10, and $100 \mu \mathrm{m}$ particle sizes, respectively, at each sampling site (Qingdao Laoshan Mechanical Corp, CN). Air was sampled at a flow rate of $100 \mathrm{~L} / \mathrm{min}$ for $24 \mathrm{~h}$, and three days each season. A total of 108 Airborne PM samples were collected from Lanzhou city corresponding to 54 samples (18 TSP, $18 \mathrm{PM}_{10}, 18 \mathrm{PM}_{2.5}$ ) in A1, A2, A3 ${ }_{\text {summer }}$, A4, B1, $\mathrm{B} 2$ for summer, and 54 samples (18 TSP, $18 \mathrm{PM}_{10}, 18$ $\mathrm{PM}_{2.5}$ ) collected in A1, A2, A3 ${ }_{\text {winter }}$ A4, B1, B2 for winter. Every sample detected heavy metals concentrations. The samples of A2, A3, A4, and B1 in winter and A2, A3, and $\mathrm{B} 1$ in summer detected PAH concentrations.

All the quartz filters were wrapped in aluminum foil, preheated at $550^{\circ} \mathrm{C}$ for $6 \mathrm{~h}$, kept in a desiccator for $24 \mathrm{~h}$, and weighed by micro precision electronic balance (0.00001g, CP225D, Sartorius Inc., German) before use. After the collection of samples, the filters were kept in the desiccator for $24 \mathrm{~h}$ and weighed again. The filters, which detected both metals and PAHs, were cut into two pieces accurately. The weight of each piece was determined for calculating calibration coefficient. Then we used the precleaned aluminum foil to wrap the filters, and the samples were stored at $-29^{\circ} \mathrm{C}$ until detection.

Fig. 1. Sampling points are set in areas A and B. 
Table 1. Mean concentrations of metals of other selected cities $\left(\mathrm{ng} / \mathrm{m}^{3}\right)$.

\begin{tabular}{|c|c|c|c|c|c|c|c|c|c|}
\hline & Season & & $\mathrm{Pb}$ & $\mathrm{Zn}$ & $\mathrm{Ni}$ & $\mathrm{Cu}$ & $\mathrm{Cd}$ & $\mathrm{Cr}$ & Ref. \\
\hline \multirow{2}{*}{ Taiwan } & - & TSP & 574.00 & 395.00 & 15.80 & 199.00 & 8.50 & 29.30 & \multirow{2}{*}{ (Fang et al., 2003) } \\
\hline & - & $\mathrm{PM}_{2.5}$ & 37.90 & 283.00 & 11.80 & 11.50 & 4.30 & 33.50 & \\
\hline \multirow{2}{*}{ Guiyu } & - & TSP & 444.00 & 1038.00 & 10.00 & 483.00 & 7.30 & 1161.00 & \multirow{2}{*}{ (Deng et al., 2006) } \\
\hline & - & $\mathrm{PM}_{2.5}$ & 392.00 & 924.00 & 7.20 & 126.00 & 7.30 & 1152.00 & \\
\hline \multirow{2}{*}{ Lijiang } & - & TSP & 46.27 & 39.60 & 1.74 & 10.11 & - & 1.92 & \multirow{2}{*}{ (Zhang et al., 2013) } \\
\hline & - & $\mathrm{PM}_{2.5}$ & 14.21 & 59.74 & 2.79 & 8.56 & - & 4.76 & \\
\hline Chengdu & - & $\mathrm{PM}_{2.5}$ & 132.90 & 323.90 & 3.30 & 23.80 & - & 7.20 & (Wang et al., 2010) \\
\hline Beijing & - & $\mathrm{PM}_{2.5}$ & 304.00 & 480.00 & 15.00 & 35.00 & - & & (He et al., 2001) \\
\hline \multirow{4}{*}{ Delhi(India) } & \multirow{2}{*}{ Winter } & $\mathrm{PM}_{10}$ & 420.70 & 612.30 & 15.30 & 36.20 & 9.20 & 128.50 & \multirow{4}{*}{ (Singh et al., 2011) } \\
\hline & & $\mathrm{PM}_{2.5}$ & 630.80 & 825.10 & 15.30 & 125.30 & 12.60 & 80.50 & \\
\hline & \multirow{2}{*}{ Summer } & $\mathrm{PM}_{10}$ & 210.50 & 431.50 & 31.20 & 22.30 & 1.80 & 144.70 & \\
\hline & & $\mathrm{PM}_{2.5}$ & 630.80 & 825.10 & 29.50 & 65.20 & 2.40 & 74.10 & \\
\hline \multirow{2}{*}{ Spata(Greece) } & Winer & $\mathrm{PM}_{10}$ & 19.50 & - & 8.18 & - & 0.34 & - & \multirow{2}{*}{$\begin{array}{l}\text { (Vassilakos et al., } \\
\text { 2007) }\end{array}$} \\
\hline & Summer & $\mathrm{PM}_{10}$ & 6.41 & - & 14.70 & - & 0.49 & - & \\
\hline \multirow{2}{*}{ Koropi(Greece) } & Winter & $\mathrm{PM}_{10}$ & 24.70 & - & 7.15 & - & 0.35 & - & \multirow{2}{*}{$\begin{array}{l}\text { (Vassilakos et al., } \\
\text { 2007) }\end{array}$} \\
\hline & Summer & $\mathrm{PM}_{10}$ & 12.30 & - & 13.30 & - & 1.06 & - & \\
\hline Thessaloniki (Greece) & - & $\mathrm{PM}_{10}$ & 6.65 & - & 0.70 & 37.40 & 0.05 & 0.68 & (Samara et al., 2005) \\
\hline $\begin{array}{c}\text { Ceramic factories } \\
\text { (Spain) }\end{array}$ & - & $\mathrm{PM}_{10}$ & 41.30 & 34.60 & 23.40 & 94.90 & 0.24 & 3.64 & (Ana M et al., 2010) \\
\hline \multirow{2}{*}{$\begin{array}{c}\text { Cantabria Region } \\
\text { (Spain) }\end{array}$} & 2008 & $\mathrm{PM}_{10}$ & 6.20 & - & 0.90 & 3.70 & 0.30 & 2.30 & \multirow{2}{*}{ (Arruti et al., 2011) } \\
\hline & 2009 & $\mathrm{PM}_{10}$ & 6.90 & - & 1.50 & 6.00 & 0.20 & 8.90 & \\
\hline barcelonam(Spain) & - & $\mathrm{PM}_{10}$ & 200.00 & 300.00 & 7.00 & 70.00 & - & 6.00 & (Ouerol et al., 2001) \\
\hline Helsinki (Finland) & - & $\mathrm{PM}_{10}$ & 2.00 & 8.00 & 0.80 & 6.00 & - & - & (Pakkanen et al., 2001) \\
\hline USA & Florida & $\mathrm{PM}_{2.5}$ & 5.00 & 1.00 & 1.00 & 2.00 & - & - & (Olson et al., 2008) \\
\hline
\end{tabular}

\section{Pre-Treatment and Instrumental Analyses}

The concentrations of copper $(\mathrm{Cu})$, zinc $(\mathrm{Zn})$, nickel $(\mathrm{Ni})$, lead $(\mathrm{Pb})$, cadmium $(\mathrm{Cd})$, and chromium $(\mathrm{Cr})$ on particulate matters were measured based on relevant national standard methods (HJ657-2013).

The method of PAH detection was similar to previous research [10]. The sample filter was cut into strips, $2.00 \mathrm{~g} \mathrm{Na}_{2} \mathrm{SO}_{4}$ was added, and it was spiked with naphthalene-d8 (d8-Nap), acenaphthene-d10 (d10-Ace), phenanthrene-d10 (d10-Phe), chrysene-d12 (d12-Chr), and perylene-d12 (d12-Per) as per internal standards (LOT No. 7033-22, WIBBY Environmental Inc.). First, samples were extracted by shock with $30 \mathrm{~cm}^{3}$ dichloromethane for $1.5 \mathrm{~h}$, and separated by centrifuge. Then the samples were extracted by ultrasonic $1.5 \mathrm{~h}$ with $30 \mathrm{~cm}^{3}$ dichloromethane for $1.5 \mathrm{~h}$, and separated by centrifuge twice. The combined extracts were concentrated to approximately $2 \mathrm{~cm}^{3}$.

Combined extract was evaporated. The concentrated extract was transferred to a Bond Elut SI SPE column (500 mg, $3 \mathrm{~cm}^{3}$, Agilent Technologies). The column was then eluted with $8 \mathrm{~cm}^{3}$ of dichloromethane: hexane (1:1, $\mathrm{v}: \mathrm{v})$. The eluent was concentrated to $1 \mathrm{~cm}^{3}$, and added $50 \mu \mathrm{L}\left(20 \mu \mathrm{g} / \mathrm{cm}^{3}\right)$ injection internal standard (benzo[a] pyrene-d10 and fluorine-d10) for analysis.

PAH quantification was performed using gas chromatography coupled to mass spectrometry (Varian 240-MS/431-GC, Agilent Technologies), and a DB-5 chromatographic column $(30 \mathrm{~m}, 0.25 \mathrm{~mm}$ i.d., $0.25 \mu \mathrm{m}$ film thickness). Helium was used as the carrier gas, with a column flow rate of $1.20 \mathrm{~cm}^{3} / \mathrm{min}$ in constant-flow. The GC oven temperature was programmed from $50^{\circ} \mathrm{C}$ for 2 min to $200^{\circ} \mathrm{C}$ at $10^{\circ} \mathrm{C} / \mathrm{min}$, then to $260^{\circ} \mathrm{C}$ at $2^{\circ} \mathrm{C} / \mathrm{min}$, last to $290^{\circ} \mathrm{C}$ at $5^{\circ} \mathrm{C} / \mathrm{min}$ and kept for $3 \mathrm{~min}$. The $16 \mathrm{PAH}$ compounds were naphthalene (Naph), acenaphthylene (Acy), acenaphthene (Ace), fluorene (Flu), phenanthrene (Phen), anthracene (Anth), fluoranthene (Flt), pyrene (Pyr), benzo[a]anthracene (BaA), chrysene (Chr), benzo[b]fluoroanthene $(\mathrm{BbF})$, benzo[k]fluoroanthene $(\mathrm{BkF})$, benzo[a]pyrene $(\mathrm{BaP})$, dibenzo[a,h]anthracene (DahA), benzo[ghi]perylene (BghiP), and indeno[123-cd] pyrene (IcdP). 


\section{Quality Assurance and Quality Control}

An internal calibration procedure was used to quantify PAH concentrations. The correlation coefficients for the five concentration gradients ranged from 0.995 to 0.999 . The calibration standard was analyzed daily to determine the accuracy of the calibration curves.

To estimate the repeatability and accuracy of the analytical method, every sample was spiked with known amounts of surrogate standard mixtures prior to extraction. The surrogate recoveries in the $\mathrm{PM}_{10}$ were $70.2 \pm 7.5 \%$ for naphthalene-d8, $84.5 \pm 5.6 \%$ for acenaphthene-d 10 , $92.5 \pm 5.6 \%$ for phenanthrene-d10, $92.4 \pm 10.2 \%$ for chrysene-d12, and $89.0 \pm 9.4 \%$ for perylene-d 12 .

Quality control for the method was maintained by analyzing the following controls for each batch of samples: method blanks (solvent), spiked blanks (standard spiked into solvent), matrix spikes/matrix spike duplicates, and sample duplicates. The method detection limit was $1.00-$ $6.00 \mathrm{ng} / \mathrm{cm}^{3}$. For data reduction purposes, masses calculated from areas below the limit of detection were equated to zero.

\section{Results and Discussion}

\section{Metal and PAH Concentrations}

In recent years the levels of metals and PAHs bound to $\mathrm{PM}_{2.5}, \mathrm{PM}_{10}$, and TSP have been widely investigated (Table 1). In this study, the concentrations of metals bound to $\mathrm{PM}_{2.5}$ in Lanzhou were higher than those in the U.S., and among them the concentrations of $\mathrm{Pb}, \mathrm{Zn}$, and $\mathrm{Ni}$ were lower than those in other domestic cities (such as Guiyu, Chengdu, Beijing, and Taiwan), while $\mathrm{Cu}$ was 1-27 times higher than in Taiwan, Chengdu, and Lijiang [8, 11, 12]. In $\mathrm{PM}_{10}$, the concentrations of metals were lower than in Delhi, India; 10 times higher than that in Spata, Koropi, and Thessaloniki, Greece; 1-18 times higher than that in ceramic factories, Cantabria Regio, and Barcelona in Spain; and 8-100 times higher than that in Helsinki, Finland [3, 13-17]. The concentrations of PAHs were higher than those in Baoji and Changsha, China; Mexico and Chiang Mai, Thailand; Candiota, Brazil; Naples; Seoul; and Delhi $[3,6,11,18]$. In TSP, the concentrations

a)

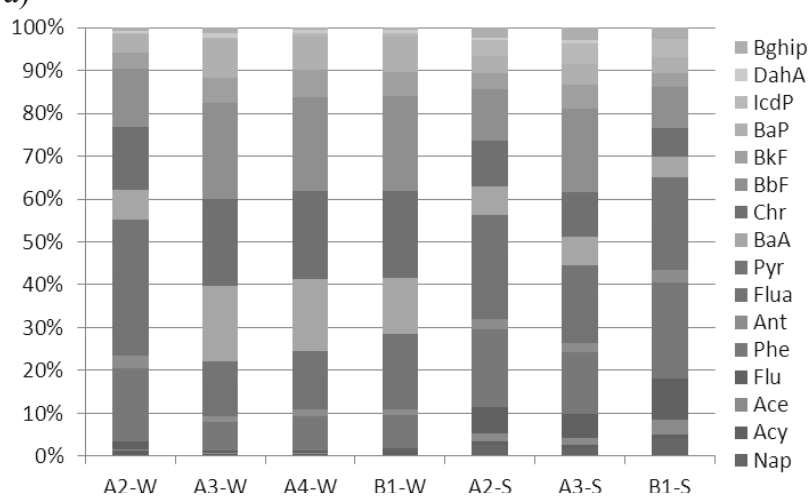

of metals were lower than in Hong Kong, Taiwan, and Guiyu $[6,12,19]$. According to previous studies showing that the $\mathrm{Cr}^{6+} / \mathrm{Cr}$ average ratio was 0.13 in particulate [19], the concentration of $\mathrm{Cr}^{6+}$ was 91-162 times higher than the Chinese $\left(0.025 \mathrm{ng} / \mathrm{m}^{3}\right)$ and World Health Organization $\left(0.025 \mathrm{ng} / \mathrm{m}^{3}\right)$ air quality standards [20]. Therefore, the air metal and PAH pollution of Lanzhou is serious.

The distributions of metals and PAHs in airborne particulates presented a characteristic of varying with the time and space. In recent years, some achievements had been made in the study on time distribution of metals in particulate matter, among which a seasonal change pattern of metals in particulate matter was shown, including seasonal trends for concentrations of $\mathrm{Pb}, \mathrm{Cu}$, and $\mathrm{Cd}$ bound to $\mathrm{PM}_{2.5} ; \mathrm{Pb}, \mathrm{Ni}, \mathrm{Cu}, \mathrm{Cd}, \mathrm{Cr}$, and $\mathrm{PAHs}$ bound to $\mathrm{PM}_{10}$; and $\mathrm{Pb}, \mathrm{Ni}, \mathrm{Cu}, \mathrm{Cd}$, and $\mathrm{Cr}$ bound to TSP, which were consistent with other studies [3]. The concentrations of $\mathrm{Pb}$ bound to $\mathrm{PM}_{10}$ in Xigu were 10 times higher than in Spata and Koropi, Greece, for winter [17]; and $\mathrm{Ni}$ and $\mathrm{Cu}$ in Xigu were 1.06 and 2.52 times higher than their values in Delhi, India, for winter [3].

There are many reports for the spatial distributions of metals and PAHs in airborne particulates, especially for the metals bound to TSP and $\mathrm{PM}_{2.5}$ in electronic and dismantling sites and scenic tourist areas. These results showed that the metals bound to TSP and $\mathrm{PM}_{2.5}$ in electronic and dismantling sites were 2.50-604 times higher than scenic tourist areas. While comparing studies we found that values were 2-70 times lower than in electronic and dismantling sites, and 2- 30 times higher than in tourism sites $[11,18]$. According to traffic conditions, the study proposed that $16 \mathrm{PAHs}$ bound to $\mathrm{PM}_{10}$ in high traffic were higher than in low traffic [15]. Vassilakos et al. (2007) reported that $\mathrm{Pb}$ bound to $\mathrm{PM}_{10}$ in high traffic areas and in low traffic areas had no obvious difference [17], which was not consistent with our studies. The reason may be that $\mathrm{Pb}$ has been phased out of gasoline in recent years.

\section{PAH Profiles in $\mathrm{PM}_{10}$}

Possible pollutant sources should be revealed by PAH profiles. Fig. 2 shows the PAH profiles in $\mathrm{PM}_{10}$ for four sampling sites in winter as well as three sampling sites in summer in Lanzhou city.

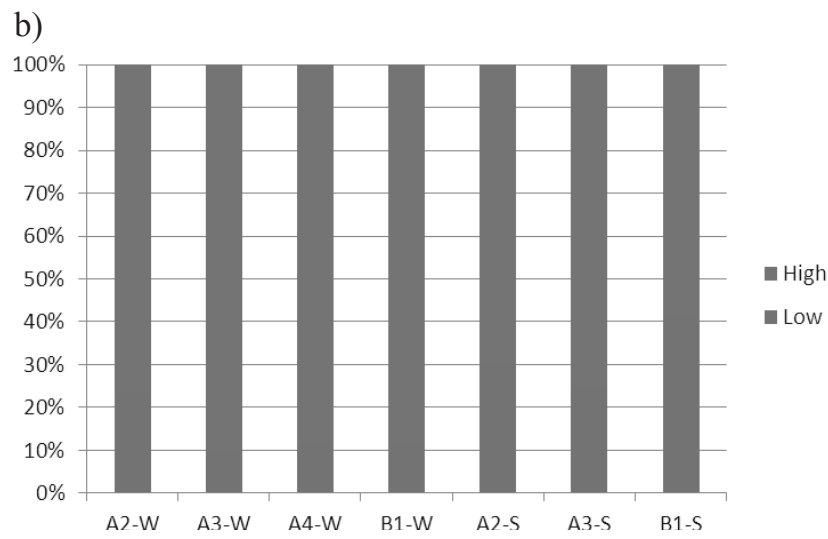

Fig. 2. PAH profiles in $\mathrm{PM}_{10}$ for: a) four sampling sites in winter and b) three sampling sites in summer in Lanzhou. 
a)

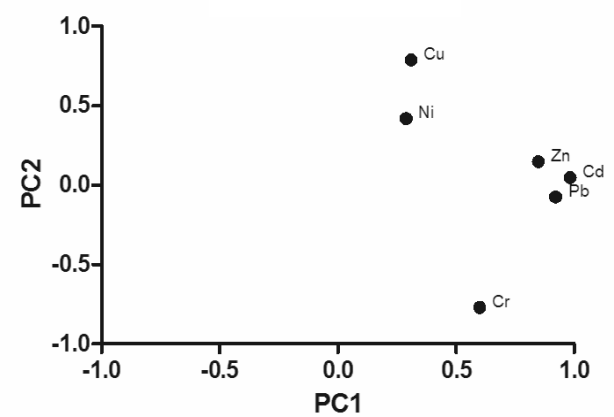

c)

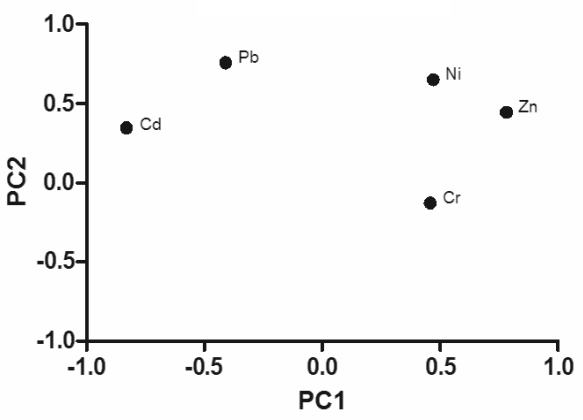

e)

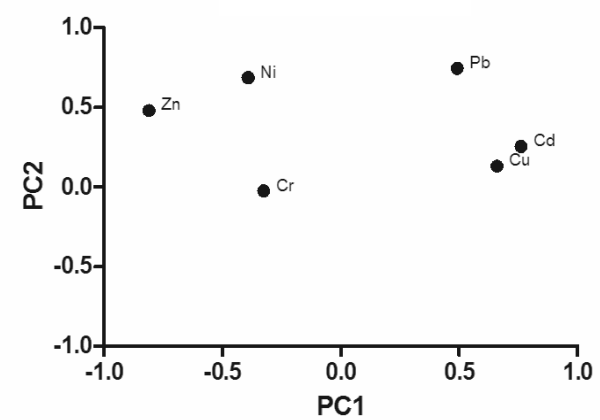

g)

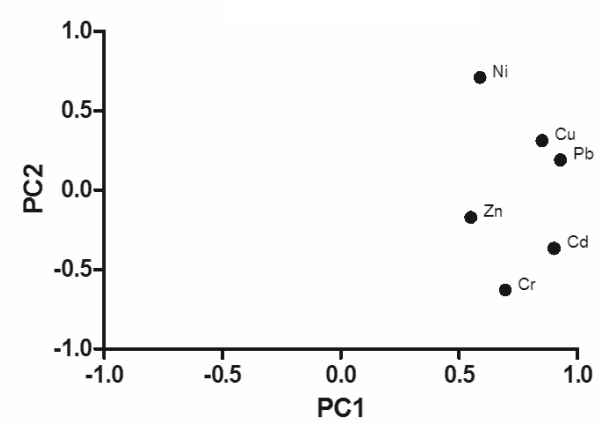

i)

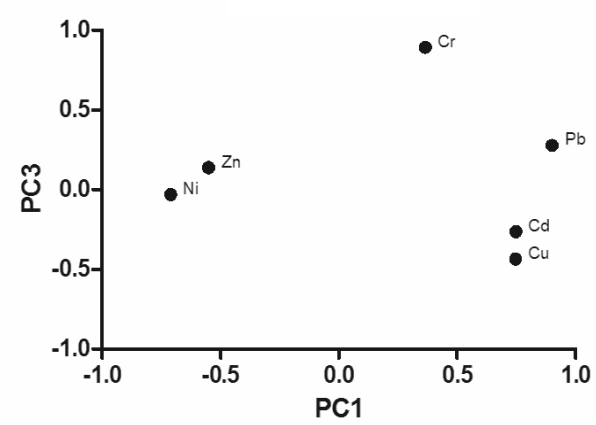

b)

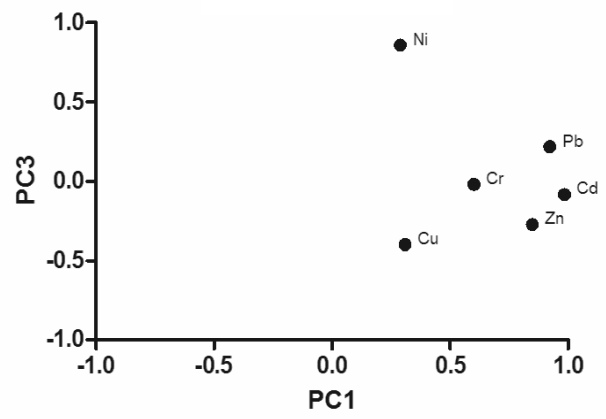

d)

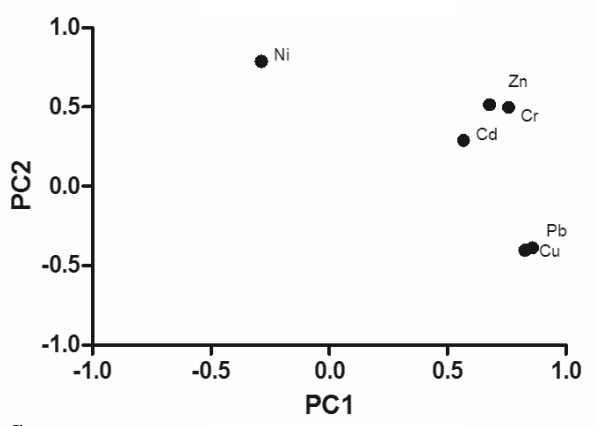

f)

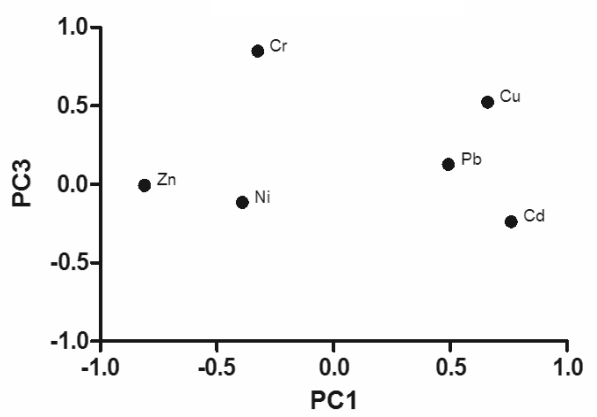

h)

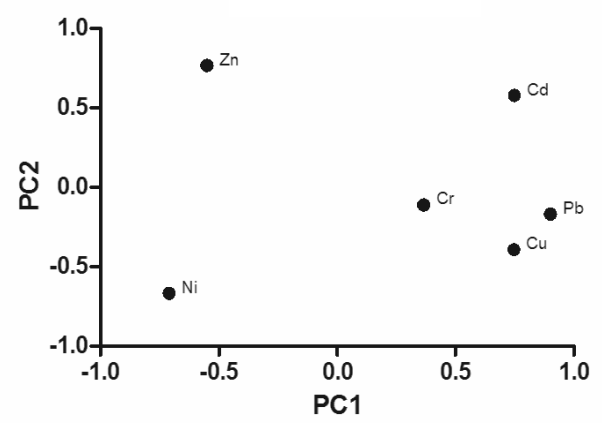

Fig. 3. PCA of the PM elemental data yielding the loading plots: a) $\mathrm{PM}_{2.5}$ Urban, b) $\mathrm{PM}_{2.5}$ Urban, c) $\mathrm{PM}_{2.5}$ Rural, d) $\mathrm{PM}_{10}$ Urban, e) $\mathrm{PM}_{10}$ Rural, f) $\mathrm{PM}_{10}$ Rural, g) TSP Urban, h) TSP Rural, i) TSP Rural.. 
For all the PAH profiles, the high molecular weight PAH (4-6 rings) show the highest fractions, ranging from $57 \%$ to $91 \%$, while the low molecular weight $\mathrm{PAH}$ fractions (2-3 rings) ranged from $9 \%$ to $43 \%$. Petroleum-derived residues generally contain relatively high concentrations of low molecular weight PAH compounds, whereas high molecular weight PAHs are formed in high-temperature combustion processes. Our findings, therefore, indicate that high-temperature combustion processes such as coal combustion and vehicle exhaust should be the dominant PAH source category bound to $\mathrm{PM}_{10}$ in Lanzhou city. This regularly coincided with the pollution levels in areas A and $\mathrm{B}$.

In winter, fractions of high molecular weight PAHs were similar in both area A and area B, except in site A2. Coal combustion for residential heating was universal behavior in Lanzhou during winter. That was the reason, although industrial pollution in area A was more serious than in area $\mathrm{B}$, and the fractions of high molecular weight PAHs were similar in A3, A4, and B1. In summer, fractions of high molecular weight PAHs were higher in area A than in area $\mathrm{B}$.

In winter, fractions of high molecular weight PAHs ranged from $76.7 \%$ to $90.6 \%$, which were higher than those in the summer, which ranged from $56.7 \%$ to $73.7 \%$. In both area $\mathrm{A}$ and area $\mathrm{B}$, fractions of high molecular weight PAHs were higher in winter than summer. BbF, $\mathrm{Chr}$, Baa, and some other high molecular weight PAHs were more abundant in winter than in summer. These high molecular weight PAH species can be used as source markers for coal combustion [21], indicating that coal combustion emission sources may be more important in the flooding season than in the dry season.

\section{Source Identification}

In order to derive information about pollution sources influencing the data, principle component analysis (PCA) has been applied to arrays of pollution variables. In this study, PCA was performed on several matrices to obtain factor loadings for the purpose of analyzing the possible source of metals bound to PM. Loading plots of different metals bound to $\mathrm{PM}_{2.5}, \mathrm{PM}_{10}$, and TSP in different areas were obtained. We also attempted to analyze the loading plots of metals and PAHs bound to $\mathrm{PM}_{10}$. One study used a combination of loading and score plots to identify possible PAH source categories, which also produced good results in our previous work [14, 21].
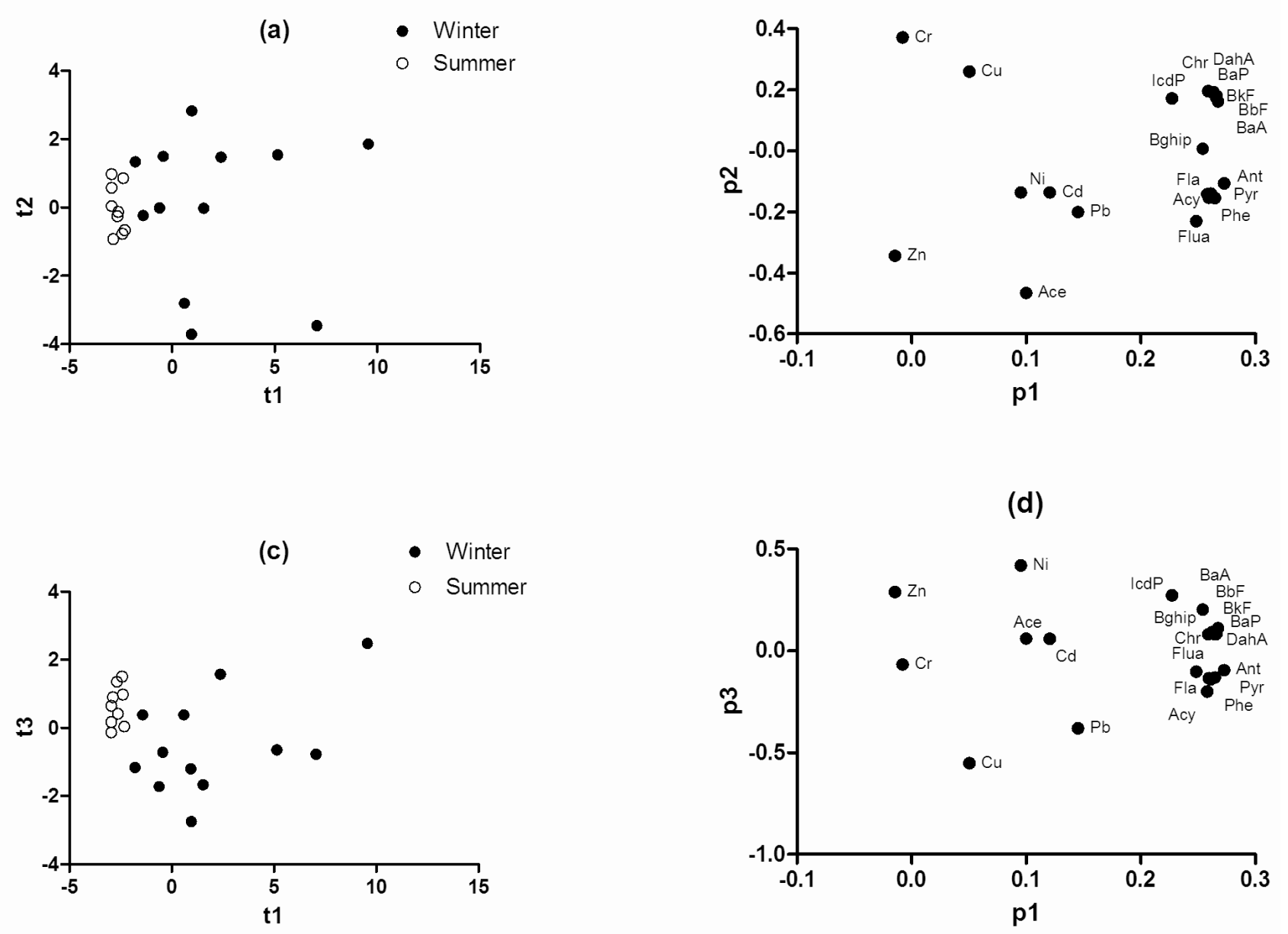

Fig. 4. PCA of the $\mathrm{PM}_{10}$ elemental data, yielding the loading plots: (a, c) season, (b, d) heavy metal and PAHs. 
PCA was applied to the PM elemental data, yielding the loading plots presented in Fig 3. PCA revealed principal components with eigenvalues $>1$, accounting for total variance $>70 \%$. Based on the data of metals bound to $\mathrm{PM}_{2.5}$ in an urban environment, three principal components were identified through the PCA method, with $92 \%$ total variance (Figs $3 \mathrm{a}, \mathrm{b}$ ). The variances of PC1, PC2, and PC3 were $51 \%, 24 \%$, and $17 \%$. Figures $3 \mathrm{a}$ and $3 \mathrm{~b}$ show that $\mathrm{Cd}$ and $\mathrm{Pb}$ exhibited high loading for $\mathrm{PC} 1, \mathrm{Cu}$, and $\mathrm{Cr}$ for $\mathrm{PC} 2$, and $\mathrm{Ni}$ for $\mathrm{PC} 3$. Pb was highly enriched in emissions from motor vehicles, and has been used previously as a source marker for vehicle aerosols [22]. Thus the vehicle source represented by PC1 may be an important source category for metals bound to $\mathrm{PM}_{2.5}$. $\mathrm{Cr}$ and $\mathrm{Cu}$ have been suggested as elemental tracers for incineration particles, and $\mathrm{Ni}$ was the marker element of residual oil combustion [23]. So the coal combustion and oil combustion may be another important source category for $\mathrm{PM}_{2.5}$ metals.

Two principal components were identified by the PCA based on the data of metals bound to $\mathrm{PM}_{2.5}$ in a rural environment, with $88 \%$ total variance (Fig. 3c). This calculation did not include the concentrations of $\mathrm{Cu}$, because of the missing values. Fig. $3 \mathrm{c}$ show that $\mathrm{Zn}$ and $\mathrm{Ni}$ exhibited high loading for PC1 and PC2, respectively. Thus, the two PCs can be interpreted as coal combustion( $\mathrm{Zn}$ ) and oil combustion(Ni) based on their correlations with key trace elements.

For urban $\mathrm{PM}_{10}$, two principal components were identified as shown in Fig. 3d, with $74 \%$ total variance. $\mathrm{Pb}$ and $\mathrm{Cu}$ showed high values for $\mathrm{PC} 1$ and $\mathrm{Ni}$ for urban $\mathrm{PC} 2$. For rural $\mathrm{PM}_{10}$, three principal components were identified with total variance of $80 \%$ (Figs 3 e,f). The variances of $\mathrm{PC} 1, \mathrm{PC} 2$, and $\mathrm{PC} 3$ were $38 \%, 23 \%$, and $19 \%$, respectively. Figs $3 \mathrm{e}$, and $3 \mathrm{f}$ show that $\mathrm{Cu}, \mathrm{Cd}$, and $\mathrm{Pb}$ exhibited high loading for $\mathrm{PC} 1, \mathrm{Zn}, \mathrm{Ni}$, and $\mathrm{Pb}$ for $\mathrm{PC} 2$, and $\mathrm{Cr}$ for PC3. The possible sources represented by principal components were vehicle emissions, coal combustion (Zn), and oil combustion (Ni) in both urban and rural environments based the on their correlations with key trace elements.

Based on the data of metals bound to TSP in an urban setting, two principal components were identified through the PCA method, with $79 \%$ total variance (Fig. 3g). For $\mathrm{PC} 1$, the variance was $59 \%$ and the high-loading element was $\mathrm{Pb}$. For PC2 the variance was $20 \%$ and the high loading element was Ni. The first possible source was vehicle emissions and the second was oil combustion.

Three principal components were identified by PCA based on the data of metals bound to TSP in a rural setting, as shown in Figs $3 \mathrm{~h}$ and 3i. The variances of PC1, PC2, and PC3 were $48 \%, 26 \%$, and $19 \%$, and the total variance was 93\%. Figs $3 \mathrm{~h}$ and $3 \mathrm{i}$ show that $\mathrm{Pb}$ exhibited high loading for $\mathrm{PC} 1, \mathrm{Zn}$ for $\mathrm{PC} 2$, and $\mathrm{Cr}$ for $\mathrm{PC}$. We propose that vehicle emissions and coal combustion may be important sources.

As particulate matter generally absorbed metals, organics, and other types of pollutants, their sources may be the same or different. Separated sources analysis of organic matter or metals bound to PM were common, but it is hard to see the simultaneous analysis of common sources of pollution of metals and organic articles. The reason may be that the nature and adsorption patterns of different types of pollutants were different. Some studies report that there was some correlations between metals and PAHs [11], and we also found significant correlation between some metals and PAHs in the previous analysis. So in this research the we attempted to jointly analyze sources of metals and organic compounds.

We also use the PCA method to analyze the possible sources of metals and PAHs bound to $\mathrm{PM}_{10}$. Three principal components were identified with $81 \%$ total variance, as the plots shown in Fig. 4. The variances of PC1, PC2, and PC3 were 59\%, 14\%, and 8\%. Factor score plot was displayed in Fig 4a, which showed that winter data were positively correlated with $\mathrm{PC} 1$ and PC2. Fig. 4b was a factor loading plot of PC1 and PC2, which showed that some PAH species and elements had high loading for principal components. BaA, BbF, Ant, and Pyr had high levels for PC1, and $\mathrm{Cr}$ had high levels for PC2. From Figs $4 \mathrm{a}$ and $4 \mathrm{~b}$ the PAH species levels that positively correlated with principal components were associated with that winter data, which positively correlated with the same principal components.

According to literature, this source appears to be from vehicles and coal, Baa, BbF, Ant, and Pyr have been identified as tracers of coal combustion [24, 25]. Elevated levels of BkF relative to other PAHs have been suggested to indicate that they are from diesel vehicles [12]. Thus, in winter the source represented by $\mathrm{PC} 1$ was a mixture source of coal combustion and vehicle emissions. $\mathrm{Cr}$ and $\mathrm{Cu}$ have been released through the progress of industry and incineration. So we proposed that the source represented by PC 2 was industry burning in winter. In addition, some of the data points for the summer also positively correlated with $\mathrm{PC} 2$, revealing that these data have contributed to the industry burning source.

Fig. 4c was a factor score plot of PC1 and PC3, which showed that some summer data were positively correlated with PC3. Meanwhile, Fig. 4d was a factor loading plot that showed $\mathrm{Ni}$ and $\mathrm{Zn}$ having high loadings. Ni was the marker element of residual oil combustion. Oil combustion was the source represented by PC3.

\section{Conclusions}

This study measured the levels of six metals bound to $\mathrm{PM}_{2.5}, \mathrm{PM}_{10}$, and TSP, and 16 PAHs bound to $\mathrm{PM}_{10}$ in ambient air collected from urban and rural Lanzhou during winter and the summer. The concentrations of pollutants were higher in the winter than in the summer, and were higher in the urban than rural environments. The pollution level in Lanzhou was higher than in cities with a thriving tourist industry, but lower than in a contaminated region and the cities with e-waste recycling industries. According to the analysis of PAHs profiles in $\mathrm{PM}_{10}$, we demonstrated that fractions of high molecular weight PAHs in winter were higher than in summer in both areas A and B, showing that 
coal combustion emission sources may be the dominant source. The PCA method was used to analyze the sources of metals bound to particulate matters ( $\mathrm{PM}_{2.5}, \mathrm{PM}_{10}$, TSP) and PAHs bound to $\mathrm{PM}_{10}$. The results showed that the first source of metals bound to particulate matters was vehicle emissions, the second coal combustion, and the third oil combustion. Moreover, the sources of PAHs bound to $\mathrm{PM}_{10}$ were mixture sources from coal combustion and vehicle emissions (first), industry burning (second), and oil combustion.

\section{Acknowledgements}

The present work was supported by the National Nature Science Foundation of China (No. U1401233,21377045).

\section{References}

1. ZHAO L., CHEN C., WANG PING., CHEN Z.G., CAO S.J., WANG Q.Q., XIE G.Y., WAN Y.L., WANG Y.F., LU B. Influence of atmospheric fine particulate matter $\left(\mathrm{PM}_{25}\right)$ pollution on indoor environment during winter in Beijing. Build. Environ., 87, 283, 2015.

2. LEQUY É., CONIL S., TURPAULT M.P., Complementary methods to distinguish organic and mineral matter in atmospheric particulate deposition and their respective nutrient inputs to temperate forest ecosystems. Aeol. Res., 12,101, 2014

3. SINGH D.P., GADI R., MANDAL T.K., Characterization of particulate-bound polycyclic aromatic hydrocarbons and trace metals composition of urban air in Delhi, India. Atmos. Environ., 45, 7653, 2011.

4. PELED R., Air pollution exposure: who is at high risk? Atmos. Environ., 45, 1781, 2011.

5. JIRIES A. Vehicular contamination of dust in Amman, Jordan. Environmentalist, 23: 205, 2003.

6. FANG G.C., WU Y.S., HUANG S.H., RAU J.Y., Review of atmospheric metallic elements in Asia during 2000-2004. Atmos. Environ., 39, 3003, 2005.

7. KONG S.F., HAN B., BAI Z.P., CHEN L., SHI J.W., XU Z., Receptor modeling of $\mathrm{PM}_{2.5}$, PM10 and TSP in different seasons and long-range transport analysis at a coastal site of Tianjin, China. Sci. Total Environ., 408,4681, 2010.

8. HE K. B., YANG F. M., MA Y. L., ZHANG Q., YAO X. H., CHAN C.K. The characteristics of $\mathrm{PM}_{25}$ in Beijing, China. Atmos. Environ., 35, 4959, 2001.

9. YU Y.J., WANG Q., NAN Z.R., ZHANG Y.P. LIN H.P., WANG S.L., Distribution Characteristics and Risk Assessment of Heavy Metal Pollutants in Air Particulate Matters in Lanzhou City. Adv. Mater. Res., 518, 961, 2012.

10. YU Y.J.,LIU Z.E., HE Y., Analysis and risk assessment of air benzo(a)pyrene and children urinary 1-hydroxypyrene in Lanzhou City. Acta Sci. Circumstant., 32, 2332, 2012.

11. DENG W.J., LOUIE P.K.K., LIU W.K., BI X.H., FU J.M., WONG M.H. Atmospheric levels and cytotoxicity of PAHs and heavy metals in TSP and $\mathrm{PM}_{25}$ at an electronic waste recycling site in southeast China. Atmos. Environ., 40, 694, 2006.

12. FANG G.C., CHANG C.N., CHU C.C., WU Y.S., FU
P.P.C., YANG I.L., CHEN M.H., Characterization of particulate, metallic elements of TSP, $\mathrm{PM}_{2.5}$ and $\mathrm{PM}_{2.5-10}$ aerosols at a farm sampling site in Taiwan, Taichung. Sci. Total Environ., 308, 157, 2003.

13. SÁNCHEZ DE LA CAMPA A.M., DE LA ROSA J.D., YOLANDA GONZÁLEZ-CASTANEDO Y., FERNÁNDEZ-CAMACHO R., ALASTUEY A., CASIMIRO PIO X.Q. High concentrations of heavy metals in PM from ceramic factories of Southern Spain. Atmos. Res., 96, 633, 2010.

14. PAKKANEN T.A., LOUKKOLA K., KORHONEN C.H., AURELA M., MAKELA T., HILLAMO R.E., AARNIO P., KOSKENTALO T., KOUSA A., MUENHAUT W., Sources and chemical composition of atmospheric fine and coarse particles in Helsinki area. Atmos. Environ., 35, 5381, 2001.

15. QUEROL X., ALASTUEY A., RODRIGUEZ S., PLANA F., RUIZ C.R., COTS N., MASSAGUE G., PUIG O. PM and $\mathrm{PM}_{25}$ source apportionment in the Barcelona Metropolitan area, Catalonia, Spain. Atmos. Environ., 35, 6407, 2001.

16. ARRUTI A., FERNÁNDEZ-OLMO I., IRABIEN A. Impact of the global economic crisis on metal levels in particulate matter (PM) at an urban area in the Cantabria Region (Northern Spain). Environ. Pollut., 159, 1129, 2011.

17. VASSILAKOS C.H., VEROS D., MICHOPOULOS J., MAGGOS T., O'CONNOR C.M. Estimation of selected heavy metals and arsenic in $\mathrm{PM}_{10}$ aerosols in the ambient air of the Greater Athens Area, Greece. Journal of Hazardous Materials, 140, 389, 2007.

18. ZHANG N.N., CAO J.J., XU H.M., ZHU C.S. Elemental compositions of $\mathrm{PM}_{2.5}$ and TSP in Lijiang, southeastern edge of Tibetan, Plateau during pre-monsoon period. Particuology., 11, 63, 2013.

19. DAI T.G., LUO Y.H., LIANG K. Contents and form of heavy metal in $\mathrm{PM}_{10}$ of different diameters. Journal of Earth Sciences and Environment, 28, 87, 2006 [in Chinese].

20. WHO, 2005. Air Quality Guidelines Global Update. World health Organization. On the internet at. http://www.eurowho. int/document/E87950.pdf.

21. LIU Y., WANG S.Y., LOHMANN R., YU N., ZHANG C.K., GAO Y., ZHAO J.F., MA L.M. Source apportionment of gaseous and particulate PAHs from traffic emission using tunnel measurements in Shanghai, China. Atmos. Environ., 107, 129, 2015.

22. WATSON E., COOPER D. Ventricular tachycardia associated with ondansetron and phenylephrine administration during spinal anaesthesia in pregnancy. International Journal of Obstetric Anesthesia, 23, 293, 2014.

23. KULSHRESTHA A., SATSANGI P.G., MASIH J., TANEJA A. Metal concentration of $\mathrm{PM}_{25}$ and $\mathrm{PM}_{10}$ particles and seasonal variations in urban and rural environment of Agra, India. Sci. Total Environ., 407, 6196, 2009.

24. KHILLARE P.S., JYETHI D.P., SARKAR SAYANTAN., Health risk assessment of polycyclic aromatic hydrocarbons and heavy metals via dietary intake of vegetables grown in the vicinity of thermal power plants. Food. Chem Toxicol., 50, 1642, 2012

25. JUNG K.H., YAN B.Z., CHILLRUD S.N., PERERA F.P., WHYATT R., CAMANN D., KINNEY P.L., MILLER R.L. Assessment of benzo(a)pyrene-equivalent carcinogenicity and mutagenicity of residential indoor versus outdoor polycyclic aromatic hydrocarbons exposing young children in New York city. International Journal of Environmental Research and Public Health, 7, 1889, 2010. 